\title{
A bacia hidrográfica transfronteiriça do Rio Quaraí/Cuareím: uma visão do gerenciamento integrado.
}

\author{
The river basin transboundary River Quarai / Cuareim: a vision for the integrated management. \\ Aline Andressa Bervig', Eliane Maria Foleto² \\ 'Geógrafa, Mestranda em Geografia e Geociências, Universidade Federal de Santa Maria PPGGEO/UFSM - Santa Maria - RS - Brasil \\ 2 Professora, Departamento de Geociências, Universidade Federal de Santa Maria PPGGEO/UFSM - Santa Maria - RS - Brasil
}

\section{Resumo}

Atualmente, o Plano Nacional dos Recursos Hídricos (PNRH) expõe que a água possui usos múltiplos, ou seja, para: abastecimento humano, hidroeletricidade, navegação, abastecimento industrial, irrigação, pesca, recreação, turismo e dentre outros. Por isso é fundamental saber manejá-la e conhecer a realidade dos seus usos em cada região no Planeta Terra. O objetivo principal desse trabalho foi evidenciar, de maneira introdutória, a questão do compartilhamento integrado da Bacia Hidrográfica Transfronteiriça do Rio Quaraí/Cuareím. Para a elaboração dessa revisão bibliográfica foram utilizados documentos oficiais, artigos, dissertações e teses, além de livros que abordaram o tema abordado neste artigo. O gerenciamento integrado da Bacia Hidrográfica Transfronteiriça do Rio Quaraí/Cuareím ainda é frágil, principalmente, no quesito da preservação ambiental e na eficácia do diálogo entre os países envolvidos, ou seja, o Brasil e o Uruguai.

Palavras-chaves: Bacia hidrográfica; transfronteiriça; recursos hídricos; território.

\begin{abstract}
Currently, the National Plan for Water Resources (PNRH) states that water has multiple uses for: human supply, hydropower, navigation, industrial supply, irrigation, fisheries, recreation and tourism among others. Therefore it is essential to know how to handle it and know the reality of their uses in each region on Earth. The main objective of this study was to demonstrate, in an introductory way, the issue of sharing Integrated River Basin Transboundary River Quarai/ Cuareim. For the development of this literature review official documents, articles, theses were used, as well as books about the topic covered in this article. Integrated Management of Transboundary River Basin Quaraí/Cuareim is still fragile, especially in the issue of environmental preservation and effective dialogue between the countries involved, namely, Brazil and Uruguay.
\end{abstract}

Keywords: River basin; border; water resources; territory. 


\section{INTRODUÇÃO}

A extensão de um determinado território é perceptível, principalmente, quando se manuseia um mapa ou qualquer outro modo de visualização espacial. Porém, inserindo os recursos naturais nessa representação, muitas vezes, eles acabam ultrapassando os limites territoriais e tornando-se transfronteiriços.

Conforme VALLEJO (2009):

"O conceito de território abrange desde as questões ligadas à sobrevivência, e que envolvem as relações com o substrato material, até os processos de manutenção, consolidação e expansão dos espaços dominados, ou seja, as relações de poder. Há nisso um esforço transdisciplinar de se buscar a compreensão dos mecanismos que levam à própria organização espacial, em seu sentido mais amplo."

Até o final da década de 1960, era, unicamente, o Estado que definia os processos espaciais e do território. A partir da década seguinte, 1970, o Estado começou a ser subordinado ao território, consolidando, assim, o conceito de Estado/território, caminhando para uma noção de transnacionalização até os dias atuais. SANTOS (2006).

$\mathrm{Na}$ esfera do poder, cada território, seja um Município ou até mesmo uma Nação, adquire determinada forma de gerenciamento dos seus recursos naturais, onde a água possui unidade de gestão diferenciada. Destacando as bacias hidrográficas $(\mathrm{BH})$, sabe-se que o Brasil e o Uruguai, por exemplo, possuem aquela que transpassa os seus limites territoriais, por exemplo, a BH do Rio Quaraí/Cuareím.

Para CHABALGOITY (2002)

"La gestión integrada de cuencas hidrográficas está directamente vinculada a la temática del Ordenamiento Ambiental del Territorio. El Ordenamiento Ambiental del Territorio "es un proceso dinámico dirigido a evaluar y programar el uso del suelo y el manejo de los recursos naturales en el territorio a escala nacional o local, considerando el equilibrio ecológico del mismo y por lo tanto proteger el medio ambiente y la calidad de vida de la sociedad."

Conforme exposto na citação, "a gestão integrada da bacia hidrográfica está diretamente ligada aos temas da Terra e do Meio Ambiente. O ordenamento ambiental é um processo dinâmico, e teve como objetivo avaliar e planejar o uso da terra e a gestão dos recursos naturais no território, a nível nacional ou local, considerando-se o equilíbrio ecológico da mesma e, portanto, proteger o meio ambiente e a qualidade de vida da sociedade". Nesse sentido, a temática do artigo é fundamental, uma vez que, trabalhou a questão do gerenciamento integrado em bacias hidrográficas transfronteiriças, mais em específico, a do Rio Quaraí/Cuareím. Expôs os conceitos que permeiam as bacias hidrográficas transfronteiriças, demonstrando que a temática, a mesma contribuiu, de forma breve, para a necessidade de articulação dos poderes do Brasil e do Uruguai.

\section{PROCEDIMENTOS METODOLÓGICOS}

Para a elaboração dessa revisão bibliográfica, utilizou-se da pesquisa em literaturas especializadas em autores que discutem os processos de ordenamento territorial em regiões transfronteiriças, focando na bacia hidrográfica transfronteiriça do Rio Quaraí/Cuareím, localizado na fronteira do Brasil e do Uruguai.

\section{REVISÃO BIBLIOGRÁFICA}

\subsection{Conceitos acerca da temática bacia hidrográfica transfronteiriça}

O Brasil adotou a bacia hidrográfica como a unidade territorial para a implementação da Política Nacional dos Recursos Hídricos e para a atuação do Sistema Nacional de Gerenciamento dos Recursos Hídricos. Ao fazer isso, o Brasil seguiu uma tendência já consolidada em vários países do 
Mundo, principalmente, o modelo adotado pela França.

A partir de BRASIL (1997) Lei $\mathrm{N}^{\circ}$ 9.433/1997 a gestão passa a ser por bacia hidrográfica em detrimento de uma abordagem pontual das águas, não mais se baseando em fronteiras administrativas e políticas das federações, ou seja, considerando a bacia hidrográfica uma unidade natural de circulação das águas, o que, em muitas vezes, ultrapassa as fronteiras nacionais, tratando-a como transfronteiriça, se no caso ela estiver localizada entre os limites territoriais de dois ou mais países.

MUSETTI (1999) alerta que:

"A bacia hidrográfica deve ser entendida como sendo a unidade ecossistêmica e morfológica que permite a análise e entendimento dos problemas ambientais. Ela também é perfeitamente adequada para um planejamento e manejo, buscando otimizar a utilização dos recursos humano e natural, para estabelecer um ambiente sadio e um desenvolvimento sustentado."

Nas palavras de FREITAS (2000): "a Lei $\mathrm{N}^{\circ}$ 9.433/00, configura um marco que reflete uma profunda mudança valorativa no que se refere aos usos múltiplos da água, às prioridades desses usos, ao seu valor econômico, à sua finitude e à participação popular na sua gestão".

Para KERKHOFF y LEBEL (2006):

“...nuevas formas de interpretar y vivir los territórios [...] es relevante considerar las diversas y complejas formas de entender lo relativo a participación, integración, negociación entre otros aspectos para avanzar en el desarrollo sustentable."

Há, conforme os autores acima, novas formas de interpretar e viver os territórios, ou seja, é importante considerar as diversas e complexas formas de compreensão sobre a participação, integração, negociação entre outras coisas, para promover o desenvolvimento sustentável.

Conforme DOMINGUEZ (2007), a importância da criação de uma gestão integrada da terra e manejo de bacias hidrográficas, é permitir a utilização de recursos compartilhados de maneira cooperativa, equitativa e sustentável.

A relação entre a participação, gênero, soberania, igualdade, solidariedade e sustentabilidade, no caso da água, é indissolúvel. (RAY 2007).

Para ASCKAR (2003):

Las discusiones y acciones hacia los cambios necesarios en la gestión del agua, a escala global y especialmente a escala latinoamericana, representan la confrontación de dos visiones de integración territorial. Estas visiones reconocen el principio de que territorios destruidos y fragmentados producen agua degradada. La degradación del agua dulce acompaña la degradación de los territorios que la producen, almacenan y distribuyen hacia los ecosistemas.

As discussões e ações para as mudanças necessárias na gestão da água, em escala global e, especialmente, na América Latina, representando o confronto entre duas visões de integração territorial. Estes pontos de vista reconhecem o princípio de que os territórios destruídos e fragmentados produzem água degradada/ fragmentada. E a degradação da água doce ocasiona a degradação dos territórios que as produzem, as armazenam e as distribuem e o ecossistema a acompanha.

Para DOMINGUEZ \& ASCKAR (2008):

“...los movimientos en defensa del agua hacia la defensa de los territorios y hacia una integración real desde la soberanía territorial, generando las condiciones para enfrentar esta concepción con la de la fragmentación/despatrimonialización/trasnacionalización de los bienes de la naturaleza"

Existem movimentos em defesa da água e dos territórios, visando à integração real e, a partir da soberania territorial, criando as condições para enfrentar esta concepção com a fragmentação / despatrimonialização / transnacionalização dos bens da natureza.

Um rio internacional ou transfronteiriço, que faz divisa entre dois ou mais países com o exutório principal de uma bacia hidrográfica, tem-se caracterizada uma bacia hidrográfica internacional 
transfronteiriça. A essa configuração de gestão territorial caracterizada como bacia hidrográfica internacional transfronteiriça não cabe regramentos específicos de direito internacional. (CIBIM, 2012)

O conceito de bacia hidrográfica foi introduzido pelo Direito Internacional Público e consagrado no primeiro texto multilateral pela Convenção e Estatutos Relativos ao Desenvolvimento da Bacia do Chade assinada em Fort Many (Ndjamena) em 1964, conforme mencionado por SOARES (2001).

Em 1966, a Finlândia foi sede da $52^{\mathrm{a}}$ Conferência da International Law Association (ILA), citada por CIBIM (2012), na qual foram discutidas e aprovadas as Regras de Helsinque. Essas regras estabeleceram o conceito de bacia hidrográfica internacional:

"Uma bacia hidrográfica internacional é uma área geográfica que cobre dois ou mais Estados, determinada pelos limites fixados pelos divisores de água, inclusive as águas de superfície e as subterrâneas, que desembocam num ponto final comum (Art. $2^{\circ}$ )".

Este conceito de bacia hidrográfica internacional, de 1966, corrobora os conceitos geomorfológicos apresentados anteriormente, reiterando que numa bacia hidrográfica existe um exutório principal que pode ser internacional (fronteiriço ou sucessivo). E, esse conceito permanece até os dias de hoje.

Segundo YAHN (2005) de acordo com o conceito bacia de drenagem internacional, não apenas o rio é internacional, mas sim toda a bacia da qual ele faz parte. É um conceito que leva em conta todo o ciclo d'água, pois para compreender a questão da drenagem, se faz necessário um aprofundamento no conceito de todo o ciclo hidrológico e suas etapas.

Já na $52^{a}$ Conferência da International Law Association (ILA), ocorrida em 1992, na Finlândia, foi elaborada a Convenção sobre a Proteção e o uso dos Cursos d'água transfronteiriços e dos Lagos Internacionais que entrou em vigor em 1996.

Este texto internacional de 1992 traz os conceitos de águas transfronteiriças e de impacto transfronteiriço:
"Águas transfronteiriças: quaisquer águas superficiais ou lençóis freáticos que demarcam, cruzam ou se localizam nas fronteiras entre dois ou mais Estados, sendo que no caso de águas transfronteiriças que correm diretamente para o mar, tais águas transfronteiriças terminam numa linha reta traçada nas suas respectivas desembocaduras, entre pontos da linha mais baixa de suas margens;
Impacto transfronteiriço: qualquer efeito desfavorável ao meio ambiente resultante de mudança nas condições das águas transfronteiriças causadas por uma atividade humana, cuja origem física está situada inteiramente ou em parte dentro de uma área sob jurisdição de uma Parte, dentro de uma área ou jurisdição de outra Parte. Tais efeitos sobre o meio ambiente incluem efeitos sobre a saúde humana e segurança, flora, fauna, solo, ar, água, clima, paisagem e monumentos históricos ou outras estruturas físicas ou a interação entre tais fatores; incluem, igualmente, efeitos sobre a herança cultural ou as condições socioeconômicas resultantes de alterações nesses fatores." SOARES (2001)

Os novos conceitos de águas transfronteiriças e de impacto transfronteiriço foram introduzidos pelo Direito Internacional trazendo uma questão polêmica para os rios internacionais. Polêmica sob dois pontos de vista: (i) a utilização dos recursos hídricos e (ii) os aspectos relacionados à sua proteção, em particular aqueles ligados à poluição e a gestão transfronteiriça SOARES (2001), nos dois casos considerando os usos múltiplos das águas doces internacionais.

Conforme CIBIM (2012):

"A Convenção de Helsinque de 1992 inova ao aceitar o conceito de bacia hidrográfica (Art. $2^{\circ}, \S 6^{\circ}$ ) e acolhe em seu texto os princípios da responsabilidade comum, porém diferenciada; da precaução; do poluidor-pagador; e da responsabilidade intergeracional (Art. $2^{\circ}, \S 5^{\circ}$ ). O texto da Convenção também traz medidas concretas de prevenção, controle e redução do impacto transfronteiriço (Art. $3^{\circ}$ ). Esta Convenção prevê ainda que as partes ribeirinhas cooperem numa base de igualdade e reciprocidade, especialmente por meio de acordos bilaterais e multilaterais visando à gestão compartilhada e a governança participativa. O procedimento de monitoramento das águas, bem como o intercâmbio de informações entre os países integrantes da bacia hidrográfica fazem parte deste diploma internacional." 
Tendo em vista a dificuldade de efetivação da gestão dos recursos hídricos no tocante à distribuição e uso múltiplo deste recurso natural, cabe considerar que a bacia hidrográfica como unidade territorial ganhou forma quando os Princípios de Dublin, negociados na reunião preparatória para a Rio-92, determinaram que a gestão efetiva e integrada dos recursos hídricos deveria ser baseada nas bacias hidrográficas. PORTO et al. (2008).

Em 2000, o conceito de bacia hidrográfica foi incluído na Diretiva 2000/60 da Comunidade Europeia: "a área terrestre a partir da qual todas as águas fluem, através de uma sequência de ribeiros, rios e eventualmente lagos para o mar, desembocando numa única foz, estuário ou delta" (Art. $2^{\circ}, \mathrm{n}^{\circ} 13$ ).

Neste caso, retornando a citar CIBIM (2012), a Diretiva não se limita à bacia como unidade de gestão das águas, cria uma entidade maior: a 'região hidrográfica transfronteiriça', definida como "a área de terra e de mar constituída por uma ou mais bacias hidrográficas vizinhas e pelas águas subterrâneas e costeiras que lhes estão associadas, definida nos termos do $\mathrm{n}^{\mathrm{o}} 1$ do artigo $3^{\circ}$ como a principal unidade para a gestão das bacias hidrográficas" (Art. $\left.2^{\circ}, \mathrm{n}^{\circ} 15\right)$.

Já MACHADO (2009) mencionou que a bacia hidrográfica também foi incluída pela Conferência de Berlim, em 2004, e definida como uma área cujos limites são dados por um sistema de águas. "Ora, essa área não contém somente águas, mas o território em que estão inseridas as águas - isto é, a atmosfera, o solo e o subsolo, a flora e a fauna."

A consideração da bacia hidrográfica internacional e transfronteiriça deve observar a possibilidade de governança e a viabilidade da gestão das águas. Nesta unidade territorial existe a possibilidade de conexões entre os diversos atores. A partir desta articulação, poderão ser aplicados os princípios da comunicação, do uso equitativo e razoável da água e da obrigação de não causar danos transfronteiriços, pois os atores terão como objetivo comum o uso do recurso ambiental compartilhado e a noção de gestão do território a ele integrado.

Nesse sentido, os Estados integrantes de uma bacia hidrográfica transfronteiriça compartilham o recurso hídrico. Razão pela qual devem partilhar suas práticas, trocar informações e se engajar em audiências ou consultas sobre aspectos ambientais entre os diversos atores, como recomenda o documento Environmental Law Guidelines and Principles on Shared Natural Resources, da United Nation Environmental Programme (UNEP, 1985).

\subsection{A nova agenda para a cooperação e desenvolvimento fronteiriço entre Brasil e Uruguai - a realidade atual da região transfronteiriça}

A Nova Agenda para a Cooperação e Desenvolvimento Fronteiriço constitui a mais alta instância para a cooperação e integração fronteiriça entre Brasil e Uruguai, tendo sua origem nas demandas da região fronteiriça brasileiro-uruguaia e na aproximação política entre os dois Estados-nação. Questões como o contrabando, a ilegalidade de trabalhadores, estudantes e cidadãos, e o atendimento hospitalar nos dois lados da fronteira se impõem sobre a região, demandando ações das autoridades nacionais e locais.(LEMOS, 2013)

A Nova Agenda surge em 2002, no plano das diplomacias brasileira e uruguaia, prevendo adotar ações bilaterais a fim de beneficiar a vida dos cidadãos que vivem na região de fronteira entre Brasil e Uruguai. Baseou-se em um diagnóstico de que a experiência de integração fronteiriça brasileiro-uruguaia anterior era marcada pela imprecisão e superposição de competências das unidades institucionais, com a pouca eficácia dos Comitês de Fronteira, criados no final da década de 1980.

Pode-se perceber, assim, inserida ainda na visão de (LEMOS, 2013) uma evolução institucional do processo de cooperação fronteiriça entre Brasil e Uruguai, na medida em que os dois países foram se democratizando. O primeiro passo para a criação da Nova Agenda foi dado em fevereiro de 2002, quando o Palácio Santos - sede do Ministério das Relações Exteriores uruguaio - enviou nota à Embaixada do Brasil em Montevidéu, por meio da qual apresentava o documento intitulado "Elementos para uma Política Conjunta em Matéria Fronteiriça" (PUCCI, 2010). O texto tinha como intuito, assim, determinar uma "nova agenda" para o relacionamento fronteiriço. Esse documento já apresentava a proposta de criação de uma "carteira fronteiriça", semelhante ao Documento Especial Fronteiriço, posteriormente constituído.

A Nova Agenda foi criada com o objetivo de complementar e superar os impasses da tradicional cooperação na área de fronteira, na busca de uma integração que facilitasse a vida das pessoas que vivem na região. Até então, os temas relativos à região eram tratados como internacionais, apesar do predomínio das relações inter-regionais, esbarrando nos entraves burocráticos (AVEIRO, 2006). A partir 
da Nova Agenda, passou-se a ver a população que habita a região de fronteira - os doble chapa - não mais como brasileira ou uruguaia, mas sim como fronteiriça (AVEIRO, 2006).

A Nova Agenda permitiu uma melhor articulação entre as escalas local e nacional na resolução dos problemas fronteiriços. Para (SANTOS \& SANTOS, 2005) apud (LEMOS, 2003):

“(...) a experiência da cooperação fronteiriça Brasil-Uruguai fortalece a chamada vertente federativa ou o sentido de interiorização da diplomacia. No caso brasileiro, valoriza-se a participação das autoridades do Estado do Rio Grande do Sul, bem como dos municípios gaúchos situados na faixa de fronteira com o Uruguai. No caso uruguaio, a ação dos Departamentos que lindam com o território brasileiro tendem, de igual modo, a intensificar-se. Toda essa articulação que se processa no nível local, de um lado, torna necessária a ativa participação da sociedade civil, por meio de seus representantes nas comunidades fronteiriças, e, de outro, requer, certamente, estreita coordenação entre as respectivas chancelarias. (LEMOS, 2003).

\subsection{A Comissão Mista uruguaia brasileira para o Desenvolvimento da Bacia do Rio Quaraí/ Cuareím - $\mathbf{a}$ intensificação das relações transfronteiriças}

A bacia do Rio Quaraí/Cuareím se localiza na fronteira do Brasil, no Estado do Rio Grande do Sul, e do Uruguai, conforme a Figura 1 a seguir:

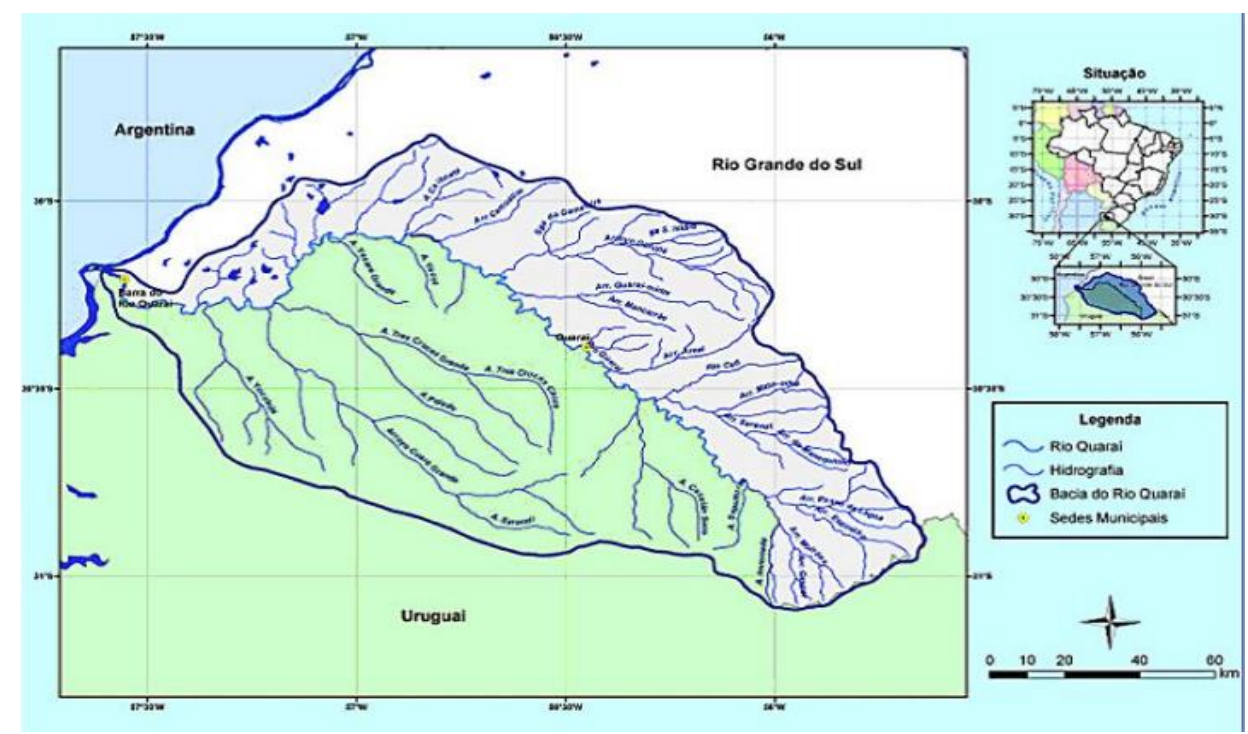

Figura 1 - Mapa de localização da Bacia Hidrográfica Transfronteiriça do Rio Quaraí/Cuareím, na fronteira do Brasil e do Uruguai. Fonte: Ministério do Meio Ambiente (2008) - Brasil

O Uruguai e o Brasil, ambos os países localizados na Bacia do Rio da Prata, com seus tratados e acordos, têm afirmado e reiterado a necessidade de uma conveniência conjunta relacionada à utilização e à gestão do recurso hídrico, que beneficiará todos os cidadãos que vivem na Bacia hidrográfica do Rio Quaraí/Cuareím. Na visão de ARCELUS \& GOLDENFUM (2005) as principais razões para a gestão coordenada, da Bacia Hidrográfica Transfronteiriça do Rio Quaraí/Cuareím são:

I. Aumento da concorrência para a utilização dos recursos hídricos;

II. A expansão da ocupação da várzea por colonos e produtores das cidades e das zonas rurais; III. O aumento do número de usuários e de lotes de obras que utilizam as águas da bacia; IV. A utilização dos cursos de água da bacia para receber descargas de resíduos e outros processos industriais semelhantes, ocasionando a diminuição na oferta dela para a população; $\mathrm{V}$. O aumento da severidade do impacto de fenômenos naturais extremos como secas e inundações, com os fenômenos adicionais efetuar mudanças no clima global;

VI. As recomendações decorrentes das conferências e fóruns internacionais sobre água, incentivando os países a estabelecer mecanismos e procedimentos para gestão partilhada das bacias transfronteiriças. 
Em relação à Bacia hidrográfica do Rio Quaraí/Cuareím existem grupos de trabalho bilateral (comissão mista) com poderes representantes definidos e designados, que têm a prerrogativa de harmonizar os planos e ações propostas para adaptar-se à legislação instituições já existentes capazes de executá-los.

Na visão também de ARCELUS \& GOLDENFUM (2005):

Este é um excelente ponto de partida para harmonizar as ações de ambos os países na gestão da bacia compartilhada e implementar essas políticas e legislação, desde que o pedido está dentro dos interesses de cada Estado. $\mathrm{O}$ aspecto crucial da aplicação da legislação não tem sido suficientemente frequentado ou subestimou a sua complexidade. As dificuldades em torno da gestão integrada da Bacia hidrográfica do Rio Quaraí/Cuareím não derivado de deficiências legais ou institucionais, mas o fracasso na implementação dos mecanismos previstos.

Em relação às funções básicas da Comissão Mista uruguaia brasileira para o desenvolvimento da Bacia hidrográfica do Rio Quaraí/Cuareím, pode-se mencionar, conforme os mesmos autores mencionados anteriormente:

Coordenação: - Coordenar a gestão e uso da água; Recomendar os planos de gestão para recursos hídricos e usos múltiplos na bacia;

Gestão da água: - Analisar, avaliar e informar sobre as aplicações existentes em relação aos usos de água do Rio Quaraí/Cuareím;- Administrar os conflitos que são gerados entre os usuários devidamente registrados;- Mediar os conflitos entre usuários;

Controle e monitoramento: - Receber as queixas ou denúncias referentes à existência de obras de represamento ou descargas não autorizadas que afetam negativamente os usuários devidamente registrados água na bacia ou o ambiente em geral;- Recomendar ou relatar arquivos sobre as sanções violações, de acordo com a legislação em vigor em cada país;

Dados e informações: - Fazer as ligações com outras instituições envolvidas no fornecimento e recepcionar os dados e informações para identificar e promover ações de interesse comum;Gerenciar um "Sistema de Informações da Água na Bacia Hidrográfica", e mantê-lo acessível para a população em geral; - Gerar uma "Atualização do Inventário da Recuperação da Água" e dos direitos para o uso e despejo na bacia; - Planejar e desenvolver atividades que tendem a difusão de regulamentos sobre a gestão dos recursos naturais;

Eventos extremos: - Analisar, manter ou alterar fluxos específicos existentes para prato principal na concessão de direitos de uso da água para o caso de secas e inundações.

A estrutura da Comissão Mista está baseada em duas subcomissões, sendo elas: a Comisión do Rio Cuareím (C.R.C) e a Agência de Águas da Bacia Hidrográfica do Rio Quaraí/Cuareím (A.C.R.C.), onde cada uma delas possui uma função específica.

Tanto a Comissão quanto a Agência de Águas da Bacia Hidrográfica (BH) do Rio Quaraí/ Cuareím possuem atividades importantes para a gestão compartilhada da BH. Entre elas pode-se citar: gerenciar a documentação da bacia, as trocas de informações referentes a ela e monitoramento contínuo da mesma e dentre outras.

\section{CONSIDERAÇÕES FINAIS}

Evidencia-se que a questão do gerenciamento integrado de bacias hidrográficas transfronteiriças é uma temática essencial nos debates acadêmicos e científicos. A necessidade de colocá-la em pauta fomenta a busca por um diálogo entre dois os mais países localizados em regiões fronteiriças.

A existência da Comissão Mista da Bacia hidrográfica transfronteiriça do Rio Quaraí/Cuareím e da Nova Agenda, demonstram a preocupação de ambos países, Brasil e Uruguai, em buscarem entrar num consenso, na gestão integrada deste recurso natural. Há a necessidade, de a médio ou longo prazo, colocá-las, cada vez mais, em prática. 


\section{REFERÊNCIAS}

ACHKAR, M., El agua no es una mercancía. Hacia una gestión sustentable del agua en Uruguay. Propuesta para una gestión sustentable de los recursos hídricos. Autoridades Autónomas de Cuencas. Uruguay Sustentable. Redes. Montevideo.(2003)

ARCELUS, Alejandro; GOLDENFUM, Joel Avruch Pojecto Piloto de Gestión Integrada de Crecidas en la Cuenca del Río Cuareím. Informe Final. OMM/GWP. Uruguay (2005)

BRASIL, Lei N ${ }^{\circ}$ 9.433, de 8 de Janeiro de 1997 - Política Nacional dos Recursos Hídricos. Disponível em: http://www.planalto.gov.br/ccivil_03/LEIS/19433.htm (Acesso em: 19 de Junho de 2013).

AVEIRO, Thaís Mere Marques. Relações Brasil-Uruguai: A Nova Agenda para a Cooperação e o Desenvolvimento Fronteiriço. Dissertação de Mestrado. Brasília: UNB, 2006. 190f.

CHABALGOITY M. La Ordenación Ambiental del Territorio: hacia una reflexión necesaria. En: En Perfil Ambiental del Uruguay 2002. Coord. Domínguez, A., R. Prieto. Ed. Nordan Comunidad. Montevideo. 185194 (2002).

CIBIM, Juliana Cassano. O desafio da governança nas bacias hidrográficas transfronteiriças internacionais: um olhar sobre a Bacia do Rio da Prata. Juliana Cassano Cibim. Tese (Doutorado) - Programa de Pós Graduação em Ciência Ambiental da Universidade de São Paulo. São Paulo, 2012

DOMÍNGUEZ, Ana, La complejidad en el abordaje territorial de las cuencas hidrográficas, en Nuevos enfoques epistemológicos, disciplinarios y didácticos en Geografía, Instituto de Profesores Artigas, CIP- IPA, Montevideo, pp. 83-91. (2007).

Ana, ASCHKAR M. "La gestIon deL agua desde La geopolítica trasnacionaL y desde los territorios de la Integración." In La gestión de los recursos hídricos: realidades y perspectivas. Tomo I / editado por Denise Soares, Sergio Vargas y María Rosa Nuño. -- Jiutepec, Morelos: Instituto Mexicano de Tecnología del Agua; Guadalajara, Jalisco: Universidad de Guadalajara, 2008.380 p. ISBN: 978-607-7563-05-1

FREITAS, V.P.(Org). Águas: Aspectos Jurídicos e Ambientais. Curitiba: Juruá, 2000. 263p.

KERKHOFF, van L. y LEBEL Lousi, Linking Knowledge and Action for Sustainable Development, Annual Review of Environment and Resources, 31:445-77. (2006)

LEMOS, Bruno de Oliveira. A nova Agenda de Cooperação e desenvolvimento fronteiriço entre o Brasil e o Uruguai: repercurssões territoriais das cidades gêmeas de Santana do Livramento e Rivera./ Bruno de Oliveira Lemos - Porto Alegre: IGEO/UFRGS, 2013. Dissertação (Mestrado) - Universidade Federal do Rio Grande do Sul. Porto Alegre/RS.

MACHADO, P.A.L. Direito dos Cursos de Água Internacionais. São Paulo: Malheiros Editores, 2009.

MUSETTI, Rodrigo Andreotti. Bacias hidrográficas no Brasil: aspectos jurídico-ambientais. Jus Navigandi, Teresina, ano 4, n. 35, 1 out. 1999 . Disponível em: <http://jus.com.br/revista/texto/1700>. Acesso em: $1^{\circ}$ ago. 2012.

PORTO, M. F. A. e PORTO, R. L. L. Gestão de Bacias Hidrográficas. Estudos Avançados, vol. 22, n 63, 2008, p. 43-60.

PUCCI, Adriano Silva. O Estatuto da fronteira Brasil-Uruguai. Brasília: Fundação Alexandre de Gusmão, 2010.

RAY, I. Women, Water and Development, Annual Review of Environment and Resources, 32:421-49. (2007). 
SANTOS, Milton, 1926-2001 A Natureza do Espaço: Técnica e Tempo, Razão e Emoção / Milton Santos. 4. ed. 2. reimpr. - São Paulo: Editora da Universidade de São Paulo, 2006. - (Coleção Milton Santos; 1)

SOARES, G. F. S. Direito internacional do meio ambiente: emergência, obrigações e responsabilidades. 1. ed. São Paulo: Atlas, 2001, 239p.

YAHN, A.G. Conflito e cooperação na bacia do Prata em relação aos cursos d'água internacionais (de 1966 a 1992). Dissertação de Mestrado apresentada no Programa de Pós-Graduação em Relações Internacionais (UNESP -UNICAMP - PUC/SP): 2005.Disponível em: http://www.santiagodantassp.locaweb.com.br/br/ arquivos/defesas/armando.pdf (Acesso em: 15 de Abril de 2013).

VALLEJO, L. R. Unidades de Conservação: uma discussão teórica à luz dos conceitos de território e de políticas públicas. Universidade Federal Fluminense, Ed. UFF. 2009. 